\title{
GOVERNMENT MOTIVATION-EMBEDDED RETURN GUARANTEE FOR URBAN INFRASTRUCTURE PROJECTS BASED ON REAL OPTIONS
}

\author{
Qingpeng MAN ${ }^{\mathrm{a}}$, Chengshuang SUN ${ }^{\mathrm{a}}$, Yuesheng FEI ${ }^{\mathrm{b}}$, Martin SKITMORE ${ }^{\mathrm{c}}$, Yong BAI ${ }^{\mathrm{d}}$, \\ Weizhuo LU \\ ${ }^{a}$ School of Management, Harbin Institute of Technology, 92 Xidazhi Street, Harbin, 15001, China \\ ${ }^{b}$ YueshengFei, Industrial Securities Co.,Ltd, 15 Jinrong St, Xicheng, Beijing, 100034, China \\ ${ }^{c}$ School of Civil Engineering and Built Environment, Queensland University of Technology, \\ Gardens Point, Brisbane,Q4001, Australia \\ ${ }^{d}$ Department of Construction Management and Engineering, North Dakota State University, Fargo, \\ ND 58102-6050, USA \\ ${ }^{e}$ Construction Engineering and Management, Department of Civil, Environmental and Natural Resources \\ Engineering, Luleå University of Technology, 97187, Luleå, Sweden
}

Received 13 Mar 2015; accepted 14 Oct 2015

\begin{abstract}
Governments usually guarantee the amount of investment income to private sector partners to encourage their participation in Public-Private Partnership urban infrastructure development projects, with the 'float return on investment guarantee' being the main method in use by the Chinese government today. The current problems with the float return on investment guarantee are analysed and a guarantee approach with embedded motivatio nal behaviour is presented as an alternative. A pricing method option is then introduced as the motivation-embedded return guarantee has similar characteristics to real options. From this, a valuation model is developed that provides the basis of a new systematic method for calculating the government guarantee value.
\end{abstract}

Keywords: urban infrastructure, government guarantee, real options, motivation behaviour.

\section{Introduction}

For a long time, much needed infrastructure development in developing countries and emerging markets has been greatly restricted due to lack of finance (Chen 2002), and China is no exception (Pan, Ma 2007). Since the mid1990s, Chinese urbanisation has developed rapidly, growing at around one per cent per year. By the end of 2012, China's urban population had accounted for over 52 per cent of the county's total population (National Bureau of Statistics of China 2013), with approximately 71 million city dwellers. As a result, the social demand for urban infrastructure has increased rapidly and it is predicted that the aggregate investment needed in Chinese urban infrastructure from 2011 to 2015 will be between 20 trillion and 36 trillion RMB (Beilin 2013) ( 1 USD $=6.1895$ RMB in December 2014). The debt caused by urban infrastructure projects by 2010 , however, was estimated to be 86.5 per cent of all of Chinese local government debts, with 79.01 per cent of that being in bank loans (National Audit Office of the People's Republic of China 2011). This suggests that government financial support alone is unlikely to be sufficient to meet the demands on China's urban infrastructure capital. Some external contribution is therefore needed, making it necessary to attract foreign capital and domestic non-government capital. An increasingly popular approach to this is through the collaboration of local governments and private investors by Public Private Partnerships (PPPs) such as BOT, TOT, PFI, DBFO (Van Ham, Koppenjan 2002).

Urban infrastructure projects also have long construction and operation periods that involve many risks in their financing, construction, operation and maintenance (Grimsey, Lewis 2002; Ahwireng-Obeng, Mokgohlwa 2002), and PPPs provide a structured collaboration model for risks, costs and income to be shared or reassigned by the public sector and private investors by using long-term contracts (Lehman, Tregoning 2004). In doing this, and in order to attract foreign and domestic non-government capital, China's host governments provide a guaranteed minimum return on investment (ROI) to private investors to reduce their risk and encourage their involvement (Ceran 2002; Fan et al. 2007).

Corresponding author: Chengshuang Sun

E-mail: chshsun@hit.edu.cn 
The prospects of obtaining at least a reasonable return is an essential prerequisite to motivate investors, but profit may be acquired through monopoly management of investors due to the monopolistic nature of urban infrastructure. It is therefore necessary for the government to restrict investors' income caused by a monopolistic situation. The government has the right to share high-expected project returns. To do this in PPPs in China, in addition to setting a minimum ROI for the private investor, the local government sets a maximum ROI too.

These ROI guarantees provided by the Chinese government embody three aspects: concessionary management, ROI and investment climate (Feng, Ju-e 2008; Luo 2008; Wang et al. 2006). The minimum ROI guarantee, in particular, is very important for private investors and the most effective in attracting non-government capital investors (Guo-an et al. 2004; Sun et al. 2007; Xia, Li 2009). A fixed ROI guarantee or disguised fixed ROI is banned by the central Chinese government (State Planning Commission of the People's Republic of China et al. 1995; Ministry of Construction of the People's Republic of China 2005; National Development and Reform Commission of China et al. 2015), so the ROI of urban infrastructure projects in China can only be the float ROI method. This means that the local government reaches an agreement with project company on the upper and lower limits of their ROI (Li-na 2004). When the actual ROI is beyond the upper limit, the income caused by the extra ROI is taken by the government as revenue, but all the income goes to the project company when the actual ROI is below the upper limit and the government compensates the project company when it is below the lower limit.

The method does create motivational problems though, as the compensation provided to underperforming companies with low actual ROIs offers little incentive to improve. Similarly, the cap on high ROIs provides no incentive to perform any higher. This paper presents a return guarantee approach with embedded motivational behaviour aimed at correcting this situation. With this approach, project company earning below the set minimum ROI are reimbursed if this is due to government policy, while those earning above the set maximum ROI are provided with an inducement (such as a tax break) to continue doing so. Because this approach has two threshold mechanisms, this paper studies this form of government motivation-embedded return guarantee based on barrier option theory.

\section{Literature review}

Early studies of government guarantees began with the free cash flow (FCF) method. Its main defect, however, is an inability to capture the flexibility of project management and strategic interaction, which has been gradually exposed with the development of risk management theory. Hayes and Garvin (1982) realized that, when the discounted cash flow (DCF) method was used to analyse projects containing great uncertainties, it can underesti- mate investment opportunity - leading to shortsighted decision-making or underinvestment. Myers (1990), who first proposed the adjusted present value (APV) approach, observed that the DCF method had inherent limitations when it was used to evaluate strategic management options or huge investment risks. Both the DCF and APV methods are developed from the FCF method and they can therefore be classified as FCF-based methods. FCFbased methods have special characteristics in pricing guarantee values. The first is typically considering invest processes as reversible. This means the investments could be recouped if actual profit is lower than anticipated profit. But the facts, however, indicate that most investments are irreversible (Eschenbach et al. 2007). The second characteristic is supposing there is only one chance to make an investment decision and the investment opportunity cannot be postponed. This means that investment decision makers are only passive selectors and cannot change their decisions in the project life time. There are, however, many opportunities to make or change decisions in the project life time (Han, Park 2008). If decision makers are uncertain about the project foreground, they can postpone the investment until they obtain more information to make decisions for next stage. FCF-based methods neglect the time or chance selectivity of investment decisions. The third characteristic of FCF-based methods is accurately forecasted of net cash flows. One of their important prerequisites is that net cash flows at each time point can be forecasted accurately. In an uncertain investment environment, net cash flows are hard to calculate accurately. FCF-based methods neglect the uncertainty of projects. Because of these characteristics, FCF-based methods work well for a short-term project, but may lead an incorrect decision with a long-term project. Urban infrastructure projects always have long-term life cycle with different stages, uncertainties and high risks and are therefore unsuitable for FCF-based methods. As Myers (1990) points out, the option method has an obvious potential for use with long-term, uncertain projects.

The first application of the option method in the value of guarantees was by Merton (1977), who evaluated loan guarantees provided by the U.S. government. Real options (ROs) methods have been developed as option methods sometimes do not work well when guaranteed subjects have no real trades and their prices are discrete. Jones and Mason (1980) have constructed a value equation for loan guarantees using a ROs method from the perspective of government guarantees for an enterprise's preferred debt and junior debt in the belief that the fiscal cost of government could be reduced through regulating the proportion of these two types of debt. Zhang (1999) calculated the value of the full guarantee, partial guarantee and debt guarantee using the real option method. Zhang et al. (2006) established a value model for government guarantees for float ROI and purchasing agreements. These studies examined the pricing of government guarantees from different perspectives and assume the 
guarantee period to be equated with the concession period. However, concessionaires cannot settle with the government until the end of the concessionary period, which means the government guarantees are executed many times during the concession period. In China, guarantees are always executed annually, based on demand quantity or return. Considering the characteristics of the float ROI, this paper takes the time node when ROI reaches the upper/lower limit designated in the contract as the execution time of guarantees, as shown in Figure 1. Thus, construction times are reduced; effectively motivating increased investor enthusiasm and business creativity, so the level of guarantees can be reduced accordingly. Hence, government financial risk is also reduced ( $\mathrm{Li}$ et al. 2011).

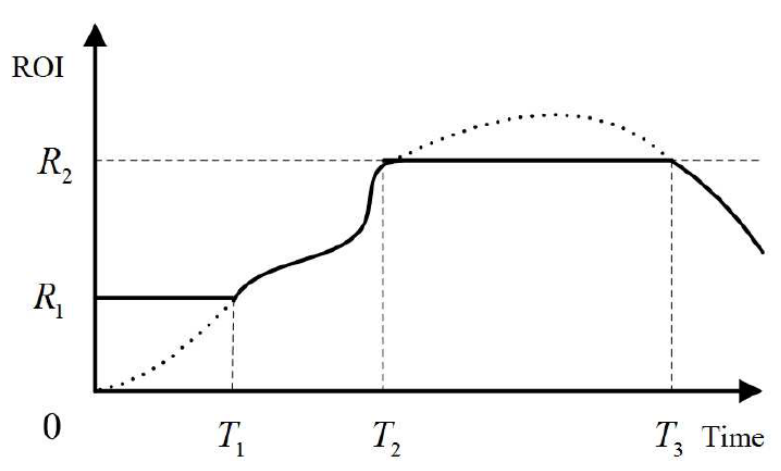

Fig. 1. Float return guarantee

In Figure 1, the solid line indicates the actual ROI of the project company, $R_{1}$ and $R_{2}$ indicate the lower and upper limits of ROI respectively, such that the ROI is never less than $R_{1}$ and never more than $R_{2}$, with the government making up any deficit below $R_{1}$ in time $\left[0, T_{1}\right]$ and extracting any surplus above $R_{2}$ in time $\left[T_{2}, T_{3}\right]$.

1. Float ROI changes the expected return of investors and redistributes project risk through adjusting the upper and lower returns of investment. If the range of float ROIs could not be properly controlled, the government would have a contingent liability. Although the liability is not paid immediately, there is still an estimated liability for the government. If the ROI lower limit $\left(R_{1}\right)$ is set too high and cannot match the government's ability to pay, the government will face considerable financial pressure (Houskamp, Tynan 2000; Mody, Patro 1996).

2. Non-government investors inevitably require increases of $R_{2}$. If the $R_{2}$ is too high for the project company to achieve, the government loses control of the guarantee. However, if the $R_{2}$ is low, the nongovernment investors have less incentive to invest.

3. An underperforming project company may just settle for $R_{1}$ and continue to underperform, which increases financial pressure on the government (Alonso-Conde et al. 1997; Mody, Lewis 1997).

4. Parting with the surplus above R2disincentivises the project company to seek a ROI above $R_{2}$. The project company may even keep the actual return lower than $R_{2}$ by increasing cost or other ways that cause unnecessary waste, reduce operational efficiency, and affect the quality of urban infrastructure provision (Zhang, Guo 2009).

In this paper, we propose a motivation-embedded ROI guarantee method aimed at solving these problems. With this new approach, the project company is compensated for an ROI $>0$ below $R_{1}$ only if it is due to government policy, otherwise the company must carry its own losses. In addition, when the ROI exceeds $R_{2}$, the government motivates the project company to some extent, such as by a reduced amount of taxation on the company's general revenue.

\section{Methodology}

\subsection{Theory selection}

ROs have three typical characteristics of being uncertain, time-selective and irreversible (Wong 2007). With the government granting franchise rights to project company, urban infrastructure projects also have these three typical characteristics. After the first phase franchise, if the products or services provided by project company meet the requirements of the government, the project company will have the right to decide whether to continue the franchise rights after they forecast future market changes. Future market changes involve the uncertain selection of franchise rights representing time-selection. If the project company decide to continue the franchise and renew the contract with the government, it will continue to invest in urban infrastructure projects. This is because, with the long operation period involved, most of the investment results in fixed assets that have low fluidity and all or part of the investment is irreversible.

Under such uncertain conditions, the government's franchise guarantee is a growth option which is one kind of real options. When the first franchise right expires and the production or services provided by the project company meet the government's requirements, the project company has the option of the franchise right for a limited period. If the project company forecast a profit, their preference is to exercise the option as it is a growth option (Kulatilaka, Perotti 1998). This option causes asymmetry in the gains and losses of the project company. If the uncertainties are conducive to a positive direction, the project company will exercise the option to obtain greater benefits. Otherwise, the project company will abandon the option to avoid making a greater loss. The government guarantee can provide future investment opportunities for the project company. This is of great significance to project company (Chiara et al. 2007). Therefore, we use growth option theory to study the government guarantee.

\subsection{Description of value changes}

Geometric Brownian motion is a special Markov process and is widely used to describe security prices in standard finance theory. Although there are some limitations, 
empirical studies show that geometric Brownian motion can describe project prices changes well between 70 to 80 years (Luenberger 1998; Jing et al. 2012). Both project value and project price are identically distributed over a long period, as project value is a result of the mean reversion of project price over time. Because of the long period of time taken in the construction and operation of urban infrastructure projects, the difference between the mean reversion results of projects prices and projects values is only marginal. More importantly, geometric Brownian motion can provide an analytical solution that can be used to determine the effects on real option values and government guarantee decisions caused by uncertainties (Mulvey et al. 1997).

Geometric Brownian motion can be expressed by:

$$
d x(t)=a d t+b d z
$$

where $a$ and $b$ are constants.

The drift rate and variance rate are assumed to be constant in geometric Brownian motion. These two rates in the value change process are functions of time $t$ so that, according to the ITO process:

$$
d x=a(x, t) d t+b(x, t) d z
$$

where the drift rate of $x$ is $a$ and the variance rate of $a$ is $b^{2}$.

According to the ITO theorem, the value, $V$, is a function of time $t$, from the following procedure:

$$
d V=\left(\frac{\partial V}{\partial x} a+\frac{\partial V}{\partial t}+\frac{1}{2} \frac{\partial^{2} V}{\partial x^{2}} b^{2}\right) d t+\frac{\partial V}{\partial x} b d z
$$

where the drift rate of $V$ is $\left(\frac{\partial V}{\partial x} a+\frac{\partial V}{\partial t}+\frac{1}{2} \frac{\partial^{2} V}{\partial x^{2}} b^{2}\right)$ and the variance rate of $V$ is $\left(\left(\frac{\partial V}{\partial x}\right)^{2} b^{2}\right)$. This is used to cal-
culate project value.

\subsection{Pricing model}

Project value $P$ follows geometric Brownian motion and therefore:

$$
\frac{d P}{P}=\mu d t+\sigma d z
$$

where $P$ is the project value; $\mu$ is the expected rate of return of the project; $\sigma$ is the variance of the expected rate of return, which represents the uncertainty of the return, and $d z$ is a random disturbance term.

From Eqn (3), the growth option of project $F$ is:

$$
d F=\left(\frac{\partial F}{\partial P} \mu P+\frac{\partial F}{\partial t}+\frac{1}{2} \frac{\partial^{2} F}{\partial P^{2}} \sigma^{2} P^{2}\right) d t+\frac{\partial F}{\partial P} \sigma P d z
$$

The discrete forms of Eqns (4) and (5) are:

$$
\Delta P=\mu P+\sigma P \Delta t
$$

$\Delta F=\left(\frac{\partial F}{\partial P} \mu P+\frac{\partial F}{\partial t}+\frac{1}{2} \frac{\partial^{2} F}{\partial P^{2}} \sigma^{2} P^{2}\right) \Delta t+\frac{\partial F}{\partial P} \sigma P \Delta z$

where $d z$ and $\Delta z$ are random disturbance terms.

To remove the random disturbance term and construct a risk-free investment portfolio, a risk investment portfolio $\Pi$ is constructed with government guarantee $F$ and project value $P$ :

$$
\Pi=-F+\frac{\partial F}{\partial P} P .
$$

After $\Delta t$ time, the risk investment portfolio is:

$$
\Delta \Pi=-\Delta \mathrm{F}+\frac{\partial F}{\partial P} \Delta P .
$$

Substituting Eqns (6) and (7) into Eqn (9):

$$
\Delta \Pi=\left(-\frac{\partial F}{\partial t}-\frac{1}{2} \frac{\partial^{2} F}{\partial P^{2}} \sigma^{2} P^{2}\right) \Delta \mathrm{t} .
$$

There is no random disturbance term $\Delta z$ in Eqn (4) and hence after $\Delta t$ time the $\Pi$ must be a risk-free investment portfolio:

$$
\Delta \Pi=r \Pi \Delta t
$$

where $r$ is the risk-free interest rate.

Substituting Eqns (8) and (9) into Eqn (11):

$$
\left(-\frac{\partial F}{\partial t}-\frac{1}{2} \frac{\partial^{2} F}{\partial P^{2}} \sigma^{2} P^{2}\right) \Delta t=r\left(-F+\frac{\partial F}{\partial P} P\right) \Delta t .
$$

After transformation, Eqn (12) can be expressed by:

$$
\frac{1}{2} \sigma^{2} P^{2} \frac{\partial^{2} F}{\partial P^{2}}+r P \frac{\partial F}{\partial P}+\frac{\partial F}{\partial t}-r F=0
$$

which is the celebrated Black-Scholes equation (Black, Scholes 1973). According to the basic theory of ROs (Black, Scholes 1973), the expected value of the growth option on the expiry date is $\max \left(P_{T}-C, 0\right)$, where $P_{T}$ is the project value on the expiry date and $C$ is the initial investment cost. After solving Eqn (13), the pricing equation is:

$$
F=P N\left(d_{1}\right)-C e^{-r T} N\left(d_{2}\right),
$$

where:

$$
d_{1}=\frac{\ln (P / C)+\left(r+\sigma^{2} / 2\right) T}{\sigma \sqrt{T}}
$$

$$
d_{2}=\frac{\ln (P / C)+\left(r-\sigma^{2} / 2\right) T}{\sigma \sqrt{T}}=d_{1}-\sigma \sqrt{T}
$$

and $N(x)$ is the cumulative distribution function of the standard normal distribution. 


\subsection{ROI changes}

Urban infrastructure provides basic services and the general foundation of the urban economy, social development and people's lives. It is the primary condition for city survival and development and the material basis of urban economic development (Ministry of Housing and UrbanRural Development of China 1999). The service/production price of urban infrastructure has a direct impact on the economics of local government and local government has the right and ability to keep control of the price (Stark 1974). As mentioned in Tam's study (1999), project companies have little chance of adjusting price when in the process of negotiation or operation. The Chinese government has developed a series of laws and regulations to prevent project companies acquiring huge profits. These laws and regulations can be divided into three levels. The top-level laws are the Anti-monopoly Law of the People's Republic of China (Standing Committee of the National People's Congress of China 2007) and the Pricing Law of the People' Republic of China (Standing Committee of the National People's Congress of China 1997), which stipulates that infrastructure service/production must be priced by government. Project companies have the right to advise on the price but this must within a reasonable range of the government guidance price. The second level regulations comprise the Measures Concerning Curbing the Making of Exorbitant Profits (State Council of the People's Republic of China 2011) and Prohibition of Acts of Price Monopoly Tentative Provisions (National Development and Reform Commission of China 2003). These stipulate that the profits for infrastructure service/production must within a reasonable range of the average profits made in the same region, at the same time and with the grade. Based on these two regulations, every province in China has guidance prices for different regions. The third level regulations consist of the Financial Guideline for Government and Public-Private Partnership (Ministry of Finance of China 2015) and Guideline on Carrying out Public-Private-Partnership (National Development and Reform Commission of China 2014), which stipulate that the profit rates for infrastructure service/production should be based on the medium and long term lending rates of commercial banks. Therefore, all project companies in China have profit rates that are within the range of the government guidelines and it is not possible for them to make any huge profits. As a result, this study makes the assumption that project ROI is always lower than the upper limit of ROI. This simplifies the boundary condition for the government guarantee value model and reflects the reality of the situation.

\section{Model construction}

Suppose the loss of the project company is caused by government policy, the return level of the project company during concessionary time is lower than the secondary threshold $R^{\prime}$. This is shown in Figure 2, where the solid line indicates the actual ROI of the project com- pany. Supposing the motivation threshold value is $R_{0}$; the government motivation level is $R^{+}$; and $R^{*}$ is the actual ROI after motivation, so $R^{*}=R+R^{+}$, where $0<R_{0}<1$, $0<R^{+}<1, R>R_{0}$.

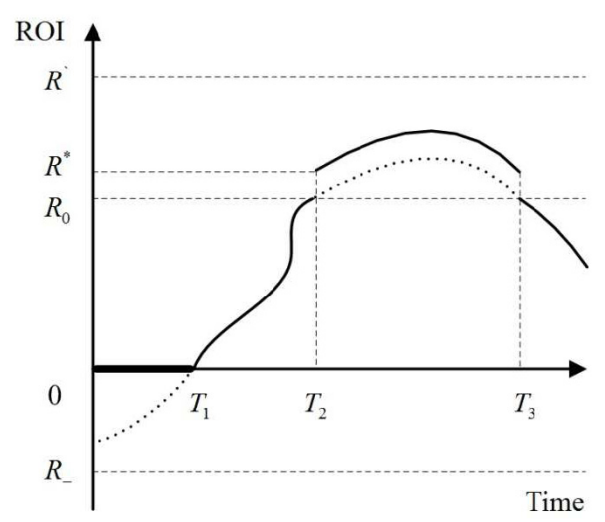

Fig. 2. Motivation-embedded ROI guarantee

When the project company is in time interval $[0$, $T_{1}$ ), the actual ROI of the project company is less than 0 , which means that the project company is operating at loss due to the public welfare policy of the government. In this case, the government subsidises the project company to assure its received ROI is at least 0 . In time interval $\left[T_{1}, T_{2}\right)$, the ROI is between 0 and $R_{0}$ and the project company obtains the actual ROI. In time interval $\left[T_{2}, T_{3}\right)$, as the actual ROI of the project company is more than the threshold value $-R_{0}$, the government should provide some motivation (e.g. tax preference) to give the project company additional $R^{+}$ROI so the project company receives a final ROI of $R^{*}\left(R^{*}=R+R^{+}\right)$. In this way, the project company is incentivised to make a high actual ROI and avoid making a low actual ROI without the possibility of making a loss or huge profit.

\subsection{Model description}

The government guarantee value is a function of project income $V$, and time $t, F(V, t)$ is the government guarantee value with embedded motivational behaviour. $F(V, t)$ can be expressed as:

$$
F(V, t)=\left\{\begin{array}{ll}
F\left(V_{R^{\prime}}, t\right)=0 & (0 \leq t \leq T) \\
F(V, t)=\lambda V & \left(V_{R_{0}}<V<V_{R^{\prime}}, 0 \leq t \leq T\right) \\
F\left(V_{R_{0}}, t\right)=0 & (0 \leq t \leq T) \\
F(V, t)=0 & \left(0<V<V_{R_{0}}, 0 \leq t \leq T\right) \\
F(0, t)=0 & (0 \leq t \leq T) \\
F(V, t)=-V & \left(V_{R_{-}}<V<0,0 \leq t \leq T\right) \\
F\left(V_{R_{-}}, t\right)=-V_{R_{-}} & (0 \leq t \leq T)
\end{array} .\right.
$$

Supposing the project return $V$ conforms to geometric Brownian motion, then:

$$
\frac{d V}{V}=\mu d t+\sigma d z
$$


where $V$ is the project return; $\mu$ is the expected return on project investment; and $\sigma$ is the variance of expected return, which represents the uncertainty of the expected return. Supposing $F$ is some call option of the project, $F$ is the function of $V$ and $t$ and satisfies the Black-Scholes equation according to the ITO theorem:

$$
\frac{1}{2} \sigma^{2} V^{2} \frac{\partial^{2} F}{\partial V^{2}}+r V \frac{\partial F}{\partial V}+\frac{\partial F}{\partial t}-r F=0
$$

Considering the boundary conditions, the government guarantee of investment has the following option characteristics:

1. When the project return is in interval $\left[V_{R_{-}}, 0\right]$, the project company actually obtains a put option, which comes into effect when $V=0$ and becomes invalid when $V$ reaches $V_{R_{-}}$.

2. When the project return $V$ reaches $V_{R_{0}}$, supposing the project company cannot obtain huge profits (meaning the project return cannot reach $V_{R^{\prime}}$ ), the project company actually obtains a call option.

If the government provides embedded motivational behaviour guarantees for a project with $M$ years of concessionary time, there will be many European call and put options during the concessionary time - even though the government only signs one contract with the project company - because of the guarantee of annual fulfilment. European options and American options are two main styles of options. A European option may be exercised only at the expiration date of the option, while an American option may be exercised at any time before the expiration date. Because the project company will make a choice to exercise or not to exercise the option at the end of each fiscal year, the options are European-style options.

$V$ is the current value of the urban infrastructure project return, and $I$ is the initial investment, then the value of the put option obtained by the project company is:

$$
F^{1}=\max (-V, 0),
$$

where $-V$ means the project company is operating at a loss due to the public welfare policy of the government.

The value of call option is then:

$$
F^{2}=\max (\lambda V, 0) .
$$

\subsection{Solution of the put option}

$F^{*}(V, t)$ is the standard put option value, which will become invalid when $V$ reaches $V_{R_{-}}$. When $V=V_{R_{-}}$the boundary condition is:

$$
F\left(V_{R_{-}}, t\right)=0 .
$$

Solving the following model in region $\left\{V_{R_{-}} \leq V \leq V_{R_{0}}\right.$, $0 \leq t \leq T\}$ :

$$
\left\{\begin{array}{ll}
\frac{1}{2} \sigma^{2} V^{2} \frac{\partial^{2} F}{\partial V^{2}}+r V \frac{\partial F}{\partial V}+\frac{\partial F}{\partial t}-r F= & \\
F(V, T)=F^{*}(V, T) & \left(V_{R_{-}}<V \leq 0\right) . \\
F\left(V_{R_{-}}, t\right)=0 & 0 \leq t \leq T
\end{array} .\right.
$$

Let $G(U, t)=F(V, t), U=-V$, then:

$$
\begin{aligned}
G(U, t)= & I e^{-r(T-t)}\left[N\left(d_{2}\right)-\left(-\frac{U}{V_{R_{-}}}\right)^{-\frac{2 r}{\sigma^{2}}+1} N\left(d_{4}\right)\right]- \\
& U\left[\left(d_{1}\right)-\left(-\frac{U}{V_{R_{-}}}\right)^{-\frac{2 r}{\sigma^{2}}+1} N\left(d_{3}\right)\right],
\end{aligned}
$$

where:

$$
\begin{gathered}
d_{1}=\frac{\ln \left(\frac{1}{U}\right)-\left(r+\frac{\sigma^{2}}{2}\right)(T-t)}{\sigma \sqrt{T-t}}, d_{2}=d_{1}+\sigma \sqrt{T-t}, \\
d_{3}=\frac{\ln \left(\frac{U^{*} I}{V_{R_{-}}^{2}}\right)-\left(r+\frac{\sigma^{2}}{2}\right)(T-t)}{\sigma \sqrt{T-t}}, d_{4}=d_{3}+\sigma \sqrt{T-t} .
\end{gathered}
$$

Substituting $U=-V$ in equation:

$$
\begin{gathered}
F(V, t)=G(U, t)=I e^{-r(T-t)}\left[N\left(d_{2}\right)-\left(-\frac{U}{V_{R_{-}}}\right)^{-\frac{2 r}{\sigma^{2}}+1}\right. \\
\left.N\left(d_{4}\right)\right]-U\left[N\left(d_{1}\right)-\left(-\frac{U}{V_{R_{-}}}\right)^{-\frac{2 r}{\sigma^{2}+1}} N\left(d_{3}\right)\right]= \\
I e^{-r(T-t)}\left[N d_{6}-\left(\frac{V}{V_{R_{-}}}\right)^{-\frac{2 r}{\sigma^{2}}+1} N\left(d_{8}\right)\right]+V\left[N\left(d_{5}\right)-\right. \\
\left.\left(\frac{V}{V_{R_{-}}}\right)^{-\frac{2 r}{\sigma^{2}}+1} N\left(d_{7}\right)\right],
\end{gathered}
$$

where

$$
d_{5}=\frac{\ln \left(-\frac{I}{V}\right)-\left(r+\frac{\sigma^{2}}{2}\right)(T-t)}{\sigma \sqrt{T-t}} ; d_{6}=d_{5}+\sigma \sqrt{T-t} ;
$$




$$
d_{7}=\frac{\ln \left(-\frac{V^{*} I}{V_{R_{-}}^{2}}\right)-\left(r+\frac{\sigma^{2}}{2}\right)(T-t)}{\sigma \sqrt{T-t}} ; d_{8}=d_{7}+\sigma \sqrt{T-t} .
$$

Equation (23) is the solution of the put option value obtained by the project company.

\subsection{Solution of the call option}

When the return of the project company exceeds $V_{R_{0}}$, the project company will gain government motivation $\lambda V$. At the expiration date of the option, the call option value is $F^{2}=\max (\lambda V, 0)$.

Considering the boundary condition and supposing the project company cannot obtain huge profits, after correction for the initial current value $V_{0}$, the call option value obtained by the project company is a standard call option. Solving the following model in region $\left\{V \geq V_{R_{0}}, 0 \leq t \leq T\right\}$ :

$$
\left\{\begin{array}{l}
\frac{1}{2} \sigma^{2} V^{2} \frac{\partial^{2} F}{\partial V^{2}}+r V \frac{\partial F}{\partial V}+\frac{\partial F}{\partial t}-r F=0,\left(V \geq V_{R_{0}}, 0 \leq t \leq T\right) \\
F(V, T)=\max (\lambda V, 0), \\
F\left(V_{R_{0}}, t\right)=0,(0 \leq t \leq T)
\end{array}\right.
$$

After solving Eqn (24), the call option value is:

where

$$
F(V, t)=\lambda V N\left(d_{1}\right)
$$

$$
d_{1}=\frac{x}{\sqrt{2 \tau}}+\frac{1}{2}(K+1) \sqrt{2 \tau}=\frac{\ln V+\left(r+\frac{1}{2} \sigma^{2}\right)(T-t)}{\sigma \sqrt{T-t}} .
$$

\subsection{Comprehensive option value}

At every expiration date of the option, the government guarantee value with embedded motivational behaviour is $F_{1}, F_{2}$, or 0 for the project company. The project company will exercise a call option or put option according to actual return. The put option value at each expiry date is:

$$
\begin{gathered}
F^{1}=I e^{-r(T-t)}\left[N\left(d_{2}\right)-\left(\frac{V}{V_{R_{-}}}\right)^{-\frac{2 r}{\sigma^{2}}+1} N\left(d_{4}\right)\right]+ \\
V\left[N\left(d_{1}\right)-\frac{V}{V_{R_{-}}}{ }^{-\frac{2 r}{\sigma^{2}}+1} N\left(d_{3}\right)\right], \\
\text { where: } d_{1}=\frac{\ln \left(-\frac{I}{V}\right)-\left(r+\frac{\sigma^{2}}{2}\right)(T-t)}{\sigma \sqrt{T-t}} ; \\
d_{2}=d_{1}+\sigma \sqrt{T-t} ; \quad
\end{gathered}
$$

$d_{3}=\frac{\ln \left(-\frac{V^{*} I}{V_{R_{-}}^{2}}\right)-\left(r+\frac{\sigma^{2}}{2}\right)(T-t)}{\sigma \sqrt{T-t}} ; d_{4}=d_{3}+\sigma \sqrt{T-t}$.

The call option value at each expiry date is:

$$
F^{2}=\lambda V N\left(d_{1}\right)
$$

where

$$
d_{1}=\frac{x}{\sqrt{2 \tau}}+\frac{1}{2}(K+1) \sqrt{2 \tau}=\frac{\ln V+\left(r+\frac{1}{2} \sigma^{2}\right)(T-t)}{\sigma \sqrt{T-t}} .
$$

The comprehensive option value is:

$$
F=P_{1}^{*} F^{1}+P_{2} * 0+P_{3} * F^{2}
$$

where $P_{1}, P_{2}, P_{3}$ is the probability of $V_{R_{-}}<V \leq 0,0<V<V_{R_{0}}, \quad V_{R_{0}} \leq V<V_{R}$.

\subsection{Example}

A project company granted the right to develop and operate a road, where the initial investment $I$ is 3 billion RMB and the government guarantee is executed annually. Suppose the volatility rate of the project value is $25 \%$ and the risk-free interest rate is $6 \%$. The government promises that the project company will gain $5 \%$ of total annual income as motivation if the annual income exceeds 1 billion RMB $\left(V_{R_{0}}=10\right)$. The project company will obtain a subsidy to meet its losses if its losses are caused by government public welfare policy and the upper limit of subsidy is 2 billion $\operatorname{RMB}\left(V_{R_{-}}=-20\right)$. The government will be relieved of its liability if the losses exceed the upper limit. The subsidy from the government is 0 if the income of the project company does not exceed 1 billion and there are no losses caused by government public welfare policy.

The probability of the annual income reaching 1 billion is $25 \%$, the probability of it not exceeding 0.5 billion is $55 \%$, the probability of running at a loss because of government public welfare policy is $20 \%$ and the maximum loss is 1.5 billion.

The government guarantee value $F$ gained by the project company is:

$$
F=25 \% * F^{1}+55 \% * 0+20 \% * F^{2}=25 \% * F^{1}+20 \% * F^{2},
$$

where $F^{1}$ can be calculated by:

$$
\begin{gathered}
d_{1}=\frac{\ln \left(-\frac{I}{V}\right)-\left(r+\frac{\sigma^{2}}{2}\right)(T-t)}{\sigma \sqrt{T-t}}= \\
\frac{\ln \left(-\frac{30}{-15}\right)-\left(6 \%+\frac{0.25 \times 0.25}{2}\right)}{0.25}=2.4076 ;
\end{gathered}
$$


$d_{2}=d_{1}+\sigma \sqrt{T-t}=2.6576$

$$
\begin{gathered}
d_{3}=\frac{\ln \left(-\frac{V^{*} I}{V_{R_{-}}^{2}}\right)-\left(r+\frac{\sigma^{2}}{2}\right)(T-t)}{\sigma \sqrt{T-t}}= \\
\frac{\ln \left(\frac{450}{400}\right)-\left(0.06+\frac{0.25^{*} 0.25}{2}\right)}{0.25}=0.1061 ;
\end{gathered}
$$

$d_{4}=d_{3}+\sigma \sqrt{T-t}=0.3561$

$$
\begin{gathered}
F^{1}=I e^{-r(T-t)}\left[N\left(d_{2}\right)-\left(\frac{V}{V_{R_{-}}}\right)^{-\frac{2 r}{\sigma^{2}}+1} N\left(d_{4}\right)\right]+ \\
V\left[N\left(d_{1}\right)-\left(\frac{V}{V_{R_{-}}}\right)^{-\frac{2 r}{\sigma^{2}}+1} N\left(d_{3}\right)\right]=
\end{gathered}
$$

$$
\begin{aligned}
& 30 * 0.9418 *[0.996-0.64 * 1.3030]+ \\
& 15 *[0.992-0.5438 * 1.3030]= \\
& 4.5794+4.2514=8.8308 .
\end{aligned}
$$

$F^{2}$ can be calculated as:

$$
\begin{aligned}
d_{1}= & \frac{x}{\sqrt{2 \tau}}+\frac{1}{2}(K+1) \sqrt{2 \tau}=\frac{\ln 10+\left(r+\frac{1}{2} \sigma^{2}\right)(T-t)}{\sigma \sqrt{T-t}}= \\
& \frac{2.3026+0.3725}{0.25}=10.7 ; \\
F^{2} & =\lambda V N\left(d_{1}\right)=0.05 * 10 * 1=0.5 .
\end{aligned}
$$

The comprehensive guarantee value $F$ is:

$$
\begin{aligned}
F= & 25 \% * F^{1}+55 \% * 0+20 \% * F^{2}=25 \% * 0.8308+ \\
& 0.5 * 20 \%=0.23077 \text { billon RMB. }
\end{aligned}
$$

\section{Discussion}

\subsection{The option characteristics of the government return guarantee}

An option is a contract that gives the buyer the right, but not the obligation, to buy or sell an underlying asset or instrument at a specified price on or before a specified date. A real option is a non-financial asset that confers the option of making a future investment. A real option is an authority to change behaviour with uncertain factors when decision-making, and the authority is owned by the project company when it makes long-term investment decisions. From this point of view, a real option is a kind of general option (Xiaocheng et al. 2008). The final in- come of a barrier option depends on not only the price of the underlying assets on expiration but also the changes in price over the life of the option, and is determined by whether or not the underlying security's price passes a certain level before the option can be exercised. Therefore, the barrier option is a form of path-dependent option (Gao et al. 2008). The barrier option can be divided into two kinds: the knockout option that is extinguished on the price of the underlying asset breaching a barrier; and the knock-in option, that becomes available upon the price of the underlying asset breaching a barrier.

In conditions of uncertain future incomes of the project company, the embedded motivational behaviour government return guarantee has the attributes of a knockin option. When the project company makes a loss due to government policy, the government compensates the loss. In this case, the project company actually obtains a knock-in put option that becomes available when the project company suffers a loss. When the income of the project company reaches the threshold value set by the government, the government will motivate the project company to some extent. In this case, the project company obtains a knock-in call option, which becomes available when the income of the project company reaches the threshold value.

Here, $V$ represents project income, $T$ represents the concession period, $V_{T}$ represents the value of $V$ at the end of the concession period, $V_{R 0}$ represents the project income when the income of the project company reaches the threshold value, $V_{R_{-}}$represents the maximum compensation that the government can give, and $V_{R}$, represents the secondary threshold value. Supposing the income of the project company exceeds $V_{R 0}$, the government gives the project company an extra $\lambda(0<\lambda<$ tax rate) times of actual income as motivation. $F$ represents the embedded motivational behaviour government guarantee value. The values of $F$ have a direct relation with $V_{T}$, as seen in Table 1.

\section{Table 1 . The values of $F$}

\begin{tabular}{c|c|c}
\hline Values of $V_{T}$ & $\begin{array}{c}\text { Actual income of } \\
\text { Project Company }\end{array}$ & Values of $F$ \\
\hline$V_{R_{-}}<V_{T}<0$ & 0 & $-V_{T}$ \\
\hline $0 \leq V_{T} \leq V_{R_{0}}$ & $V_{T}$ & 0 \\
\hline$V_{R_{0}}<V_{T} \leq V_{R}$ & $V_{T}+\lambda V_{T}$ & $\lambda V_{T}$ \\
\hline$V_{T}>V_{R}$ & $V_{R}$ & 0 \\
\hline
\end{tabular}

When project income is $V_{T}<0$ and is caused by government policy, the government will fulfil its responsibility to compensate the loss in the range of $\left|V_{R_{-}}\right|$. If the actual income of the project company is 0 , then the government guarantee value is $-V_{T}$. When $0 \leq V_{T} \leq V_{R_{0}}$, the actual income of the project company is $V_{T}$, then the government guarantee value is 0 . When $V_{R_{0}}<V_{T} \leq V_{R^{\prime}}$, the government motivates the project company with $\lambda V_{T}$, 
the actual income of the project company is $V_{T}+\lambda V_{T}$, and the government guarantee value is $\lambda V_{T}$. When the actual income of the project company exceeds the secondary threshold value $\left(V_{T}>V_{R^{\prime}}\right)$, the income that exceeds $V_{R^{\prime}}$ belongs to the government; therefore, the actual income of the project companyis $V_{R^{\prime}}$, and the government guarantee value is 0 . So, the actual income of the project company is $\max \left[0, V_{R^{\prime}}\right]$, and the government guarantee value is $\max \left[-V_{T}, 0, \lambda V_{T}\right]$.

Therefore, when $V_{T}<0$, the project company obtains a put option whose underlying asset is $V$ and expiration is $T$. When $V_{R_{0}}<V_{T} \leq V_{R^{\prime}}$, the project company obtains a call option whose underlying asset is $V$ and expiration is $T$.

\subsection{Advantages of the method}

\section{Avoiding over guarantee}

After analysing more than 1,000 infrastructure concession contracts from 1985 to 2000 in Latin America and the Caribbean, Guash (2004) found that more than 50\% of power projects and $75 \%$ water projects were renegotiated. The major reason for renegotiations is burdensome debt incurred by the government. Any guarantee promised by ROI is a direct guarantee, with explicit financial liabilities for the government. Governments should calculate the precise manpower, material and financial resources needed when they decide to make a guarantee. Furthermore, governments should estimate the costs of the guarantee and evaluate its value and risks to find a balance between the benefits and risks involved (GriffithJones, de Lima 2004). Government guarantees must meet the needs of the market and government financial capacity. It also requires that a reasonable guarantee threshold is pre-established. When the project is guaranteed by a floating ROI, although the ROI is made quite clear, the final value of the guarantee is directly associated with other factors such as purchases or sales of production/service, so its exact value cannot be pre-calculated. Once the government makes a wrong forecast of the future market, the government can incur a heavy financial liability $(\mathrm{Li}$, Tao 2014). This study proposes a new method that abandons the minimum ROI by using an exact value from the combined calculations based on different probabilities of different profit levels, which provides a quantitative description of the future market uncertainties. Because the guarantee value is made clearly, the government can avoid making a guarantee that is beyond its financial capacity.

\section{Avoiding hold-up problems and making responsibilities clear in the government guarantee}

When there is a government guarantee for an infrastructure project, the government has an information advantage in the project quality requirements, and market demand and private investors have information advantage in capital and technology. The government may be locked into an infrastructure project by private investors using opportunistic behaviours to maximise their benefits (Tiong 1997; Li et al. 2013). If the government is locked in, great fiscal subsidies may be generated. Although fiscal subsidies are a financial burden on the local economy, the probability of local government cancelling the contract is very small (Yang, Liu 2005). Because of this small probability, the project company has little risk and the situation may occur where it is over subsidised by the local government guarantee. The investment decision is partially based on the government ROI guarantee and not on any scientific feasibility analysis and ROI forecast. This can cause a high coordination cost, low management efficiency and operation profit (Hu 2007). This study proposes a new method that abandons the ROI approach. The project company is unable to hold-up the government without ROI. Another advantage of this method is that it clarifies the responsibilities of the local government and project company. Because it has no possibility of holding up the government, the project company can only focus on the risks in infrastructure construction, operation and maintenance. The government bears the social risk, political risk, legal policy risk and other risks that are not controlled by market behaviour. This accords with the principle that risk allocation should be carried out with minimal risk control cost (Ahwireng-Obeng, Mokgohlwa 2002).

\section{Motivate the project company effectively}

The float ROI guarantee is a limited motivational mode that is most effective only when the expected revenue is between the upper limit and lower limits of the investment return. There is no motivational effort at other expected revenue levels, which are detrimental for local government (Zhang, Guo 2009). Viewed from the local government's standpoint, failed infrastructure projects always lead to serious social and political effects. Local government focuses on how to avoid mistakes and the failure of infrastructure projects (Salman et al. 2007). These public and socio-economic effects caused by infrastructure projects are considered to be concerned with social value (Cheah, Liu 2006). Viewed from the standpoint of the project company, economic value is reflected in the continued cash flow generated by the project. The value of an infrastructure project is therefore one of social value and economic value. Local government and private investors have different emphases on infrastructure project value that are difficult to balance. The return revenue guarantees provided by the local government can increase both economic value and social value, although this additional value is often ignored or estimated subjectively (Cheah, Liu 2006; Chiara, Garvin 2007). The real option method adopted by this study provides an analytic solution that includes this additional value and can motivate investment from private investors (Mason, Baldwin 1988; Wang et al. 2006). Furthermore, the proposed method considers the factors affecting the project company's level of effort. If the project company's return 
level is more than the secondary threshold, the motivation mode is revenue sharing. In this mode, the benefits of private investors and local government are consistent with each other. The more effort made by the project company, the more return gained by local government and the project company. The project company will therefore do its best to lower the cost coefficient with these sharing rules, as this mode of revenue sharing has proved to be an effective motivation mode in the past (Zhang, Guo 2009).

\subsection{Limitations of the study}

There are two main limitations of this study. The first is how to determine the probability of each return level. The study first introduces a combined calculation method based on the probabilities of different project company returns. It can avoid the uncertain factors of surrounding future changes in the market and can provide an exact value. The highlighted issue in negotiation will transform the approach from one of minimum ROI to the probabilities for each level of return. One way to acquire the probabilities needed is in analysing statistical data from similar projects in the same region. Local government has an absolute information advantage, which is unfair to private/non-government investors. The second limitation is that it is difficult to find practical cases to analyse. This is the first time a method has been presented to determine the government guarantee value using probabilities of different levels of return, and therefore there is no historical probability data available. It is also difficult to obtain infrastructure information such as guaranteed value and minimum ROI from Chinese local governments. According to the Regulation of the People' Republic of China on the Disclosure of Government Information (State Council of the People's Republic of China 2007) and Guideline on Carrying out Public-Private-Partnership (National Development and Reform Commission of China 2014), such information is considered to be confidential as the believes its disclosure creates a big disadvantage in future negotiations. The study presents a method that will provide an analytic solution through strict mathematical derivation that is appropriate for the existing circumstances in China. Future research will be aimed at developing the method in the light of the prevailing situation in other countries.

\section{Conclusions}

This paper proposes a new return guarantee approach with embedded motivational behaviour. ROs theory is used to build an option pricing model and the model's feasibility is verified by an example. This is a theoretical supplement to real option theory applied to PPP urban infrastructure procurement. A systematic method is provided to determine the government's guaranteed ROI value, which can provide practical application guidelines for the development of future government policy.

Although the guarantee model proposed does not have the lower limit return guarantee that is always prom- ised in the float return guarantee model, it also has no upper limit return and the project company will obtain extra return when the income reaches the motivation threshold. This extra return plays an active role in improving the operation performance of the project company and therefore improving the efficiency and quality of infrastructure provision. The no lower limit return has a positive effect on lessening the financial burden of the government. The government is not responsible for lower limit returns and avoids contingent liability. The government only compensates the project company when it makes a loss that is due to government policy. The motivation factor has a positive effect on increasing the government's revenue. When the income of the project company reaches the motivational threshold, although the government provides the project company with extra income, it also gains tax revenues because of the higher returns of the project company:

1. The proposed guarantee model has no lower ROI limit. If the government promises a lower ROI limit, there are at least two problems: the first is that the government would have a contingent liability; the second is that financial pressure on the government may be increased, because if the actual ROI is lower than lower limit, the project company will lose their operational incentive. To solve this problem, there is no lower limit of ROI in the embedded motivational behaviour government return guarantee model. Because there is no lower ROI limit, the government does not need to bear the financial pressure. However, the government will provide compensation if the project company makes a loss due to government policy.

2. The model sets a threshold value in place of an ROI upper limit. The rational goal of private sector investors is to maximise profit and, provided they are legitimate businesspersons and do nothing to harm the public interest, a high-income level is tolerated in China. If there is an ROI upper limit, the investors only obtain income between the lower and upper limits, which restricts the project company's entrepreneurial operating capabilities and possibly a recourse to controlling the actual ROI at or below the upper limit by reducing operating efficiency, affecting the quality of urban infrastructure supply. To solve this problem, there is no ROI upper limit in the embedded motivational behaviour government return guarantee model. Instead, there is a threshold value such that, when it is exceeded by the actual ROI, the project company will not only receive their normal profit but also gain an extra reward. Thus, on one hand, the government can obtain revenue from the project income tax at the same time as motivating the project company to gain extra income by going beyond the incentive threshold.

3. To prevent the project company from acquiring huge profits, there is a second threshold value set by the government so that, when the actual ROI exceeds 
this value, the extra income is diverted to the government. Because of the public nature of urban infrastructure, however, the probability of the project company obtaining a huge profit is very low and so the assumption made here is that the project ROI is always lower than the second threshold.

\section{Acknowledgements}

This work was supported by the National Natural Science Foundation of China under Grant 71201038, 71390522, 51378160 and 71031003.

\section{References}

Ahwireng-Obeng, F.; Mokgohlwa, J. P. 2002. Entrepreneurial risk allocation in public-private infrastructure provision in South Africa, South African Journal of Business Management 33(4): 29-39.

Alonso-Conde, A. B.; Brown, C.; Rojo-Suarez, J. 1997. Public private partnerships: incentives, risk transfer and real options, Review of Financial Economics 16(4): 335-349. http://dx.doi.org/10.1016/j.rfe.2007.03.002

Beilin, F. 2013. Infrastructure financing in urbanization process of China, Review of Economic Research 13: 40-53.

Black, F.; Scholes, M. 1973. The pricing of options and corporate liabilities, Journal of Political Economy 81(3): 637654. http://dx.doi.org/10.1086/260062

Ceran, N. 2002. Private participation in infrastructure: a risk analysis of long-term contracts in power sector: PHD thesis. George Mason University, USA.

Cheah, C. Y. J.; Liu, J. 2006. Valuing governmental support in infrastructure projects as real options using Monte Carlo simulation, Construction Management and Economics 24(5): 545-554. http://dx.doi.org/10.1080/01446190500435572

Chen, A. H. 2002. A new perspective on infrastructure financing in Asia, Pacific-Basin Finance Journal 10: 227-242. http://dx.doi.org/10.1016/S0927-538X(02)00045-8

Chiara, N.; Garvin, M. J. 2007. Using real options for revenue risk mitigation in transportation project financing, Transportation Research Record 1993(1): 1-8.

Chiara, N.; Garvin, M. J.; Vecer, J. 2007. Valuing multiple-exercise real options in infrastructure projects, Journal of Infrastructure System 19: 34-39. http://dx.doi.org/10.1061/(asce)1076-0342(2007)13:2(97)

Eschenbach, E.; Lewis, N.; Baker, E.; Hartman, J. C. 2007. Real options and real engineering projects, Engineering Management Journal 19: 34-38. http://dx.doi.org/10.1080/10429247.2007.11431744

Fan, X. J. Y.; Zhao, Y.; Zhong, G. Y. 2007. Study on allocation proportion of infrastructure project financing risk, Journal of Industrial Engineering and Engineering Management 21(1): 98-101.

Feng, G.; Ju-e, G. 2008. On government vouching and its mechanisms and role in infrastructure projects, Journal of Capital Normal University (Social Sciences Edition) 3: 46-52.

Gao, F.; Guo, J. E.; Gong, L. 2008. The double barrier optionsbased research of the value of government guarantees in infrastructure projects, Journal of Industrial Engineering and Engineering Management 22(3): 19-23.

Griffith-Jones, S.; de Lima, A. F. 2004. Alternative loan guarantee mechanisms and project finance for infrastructure in developing countries. New York: Oxford University Press.

Grimsey, D.; Lewis, M. K. 2002. Evaluating the risks of Public Private Partnerships for infrastructure projects, International Journal of Project Management 20(2): 107-118. http://dx.doi.org/10.1016/S0263-7863(00)00040-5
Guash, L. 2004. Granting and renegotiating concessions - doing it right. World Bank Institute Development Studies, Washington D.C. http://dx.doi.org/10.1596/0-8213-5792-1

Guo-an, Y. U. 2004. Government guarantees on revenue level in concession contracts, Journal of Hohai University (Natural Sciences) 32(6): 707-711.

Han, H. J.; Park, C. S. 2008. A study on estimating investment timing of real options, The Engineering Economist 53: 197-229. http://dx.doi.org/10.1080/00137910802262895

Hayes, R. H.; Garvin, D. A. 1982. Managing as if tomorrow mattered, Harvard Business Review 60(3): 77-79.

Houskamp, M.; Tynan, N. 2000. Private infrastructure: are the trends in low-income countries different? New York: The World Bank-Private Sector.

$\mathrm{Hu}$, X. 2007. Case study of governments over-promise in BOT, Journal of Hohai University (Philosophy and social sciences) 9(2): 47-49.

Jing, N.; Wenxiu, H.; Qingbang, M.; Weiboyang, L. 2012. The measure of guarantee burden and risk management of infrastructure investment based on real options, Management Review 24(8): 11-20.

Jones, P. E.; Mason, S. P. 1980. Valuation of loan guarantees, Journal of Banking and Finance 4: 89-107. http://dx.doi.org/10.1016/0378-4266(80)90036-9

Kulatilaka, N.; Perotti, E. C. 1998. Strategic growth options, Management Science 44(8): 1021-1031. http://dx.doi.org/10.1287/mnsc.44.8.1021

Lehman, G.; Tregoning, I. 2004. Public-private partnerships, taxation and a civil society, Journal of Corporate Citizenship 15: 77-89.

http://dx.doi.org/10.9774/GLEAF.4700.2004.au.00009

Li, G.; Ju'e, G.; Feng, G. 2011. Empirical research on the government-guaranteed infrastructure factors and effect on the investment incentives, Operations Research and Management Science 20(1): 164-172.

Li, M. P.; Tao, L. K. 2014. An analysis of government regulation on urban Infrastructure-based on floating ROI guarantee, Journal of Southwest Petroleum University (Social Sciences Edition) 16(6): 29-34.

Li, W. X.; Peng, W. M.; Shi, B. S. 2013. Research on the holdup problem in the infrastructure project financing's government guarantee, Technoeconomics and Management Research 9: 70-75.

Li-na, S. 2004. On government surety in concession of BOT, Journal of Kunming Metallurgy College 20(3): 83-85.

Luenberger, D. G. 1998. Investment science. Oxford: Oxford University Press.

Luo, R. 2008. Analysis of current situation of government guarantee for BOT investment style in our country, Journal of Hunan International Economics University 8(4): 49-52.

Mason, S. P.; Baldwin, C. Y. 1988. Evaluation of government subsidies to large- scale energy projects, Advances in Futures and Options Research 3(3): 169-181.

Merton, R. C. 1977. An analytic derivation of the cost of deposit insurance and loan guarantees: an application of modern option pricing theory, Journal of Banking and Finance 1: 3-11. http://dx.doi.org/10.1016/0378-4266(77)90015-2

Ministry of Construction of the People's Republic of China. 2005. Several issues concerning strengthening municipal public itilities supervision.

Ministry of Finance of China. 2015. Financial guideline for government and Public-Private Partnership [online], [cited 1 June 2015]. Available from Internet:

http://jrs.mof.gov.cn/zhengwuxinxi/zhengcefabu/201504/ t20150414_1216615.html

Ministry of Housing and Urban-Rural Development of China. 1999. Standard for basic terminology of urban planning. Beijing: China Architecture and Building Press. 
Mody, A.; Lewis, C. M. 1997. The management of contingent liabilities: A risk management framework for national governments. Washington, D.C: World Bank.

Mody, A.; Patro, D. K. 1996. Valuing and accounting for loan guarantees, World Bank Research Observer 11(1): 119142. http://dx.doi.org/10.1093/wbro/11.1.119

Mulvey, J. M.; Rosenbaum, D. P.; Shetty, B. 1997. Strategic financial risk management and operations research, European Journal of Operational Research 97(1): 1-16. http://dx.doi.org/10.1016/S0377-2217(96)00222-6

Myers, S. C. 1990. Abandonment value and project life, $A d-$ vances in Futures and Options Research 4: 1-21.

National Audit Office of the People's Republic of China. 2011. Audit findings on China's local government debts. No. 35 of 2011 (General Serial No. 104) [online], [cited 15 December 2014]. Available from Internet: http://www.audit. gov.cn/n1992130/n1992150/n1992500/2752208.html

National Bureau of Statistics of China. 2013. The statistics communique on national economy and social development of China, China Statistics 3: 6-13.

National Development and Reform Commission of China, Ministry of Finance of China, Ministry of Housing and Urban-Rural Development of China, Ministry of Transport of China, Ministry of Water Resource of China, The People's Bank of China. 2015. No. 25 of 2015 Regulations on the concession management of infrastructure and utilities [online], [cited 17 June 2015]. Available from Internet: http://www.sdpc.gov.cn/zcfb/zcfbl/201504/ W020150427366817428026.pdf

National Development and Reform Commission of China. 2003. Prohibition of acts of price monopoly tentative provisions [online], [cited 1 June 2015]. Available from Internet: http://images.mofcom.gov.cn/fldj/accessory/200812/1228439272213.pdf

National Development and Reform Commission of China. 2014. Guideline on carrying out Public-Private-Partnership [online], [cited 1 June 2015]. Available from Internet: http://www.ndrc.gov.cn/zcfb/zcfbtz/201412/t20141204 651012.html

Pan, S. Q.; Ma, C. Q. 2007. Evaluation indicators system for the city infrastructure development level, Systems Engineering 25(7): 88-91.

Salman, A. F. M.; Skibniewski, M. J.; Basha, I. 2007. BOT viability model for large-scale infrastructure projects, Journal of Construction Engineering and Management 133(1): 50-63. http://dx.doi.org/10.1061/(ASCE)07339364(2007)133:1(50)

Standing Committee of the National People's Congress of China. 1997. Pricing law of the People's Republic of China [online], [cited 1 June 2015]. Available from Internet: http://www.gov.cn/banshi/2005-09/12/content 69757.htm

Standing Committee of the National People's Congress of China. 2007. Anti-monopoly law of the People's Republic of China [online], [cited 1 June 2015]. Available from Internet: http://www.gov.cn/flfg/2007-08/30/content_732591. htm

Stark, R. M. 1974. Unbalanced highway contract tendering, Journal of Operational Research Quarterly 25(3): 373388. http://dx.doi.org/10.1057/jors. 1974.72
State Council of the People's Republic of China. 2007. Regulation of the People's Republic of China on the disclosure of government information [online], [cited 1 June 2015]. Available from Internet: http:/www.gov.cn/zwgk/200704/24/content 592937.htm

State Council of the People's Republic of China. 2011. Measures concerning curbing the making of exorbitant profits [online], [cited 1 June 2015]. Available from Internet: http:// www.gov.cn/gongbao/content/2011/content_1860851.htm

State Planning Commission of the People's Republic of China, Ministry of Electric Power Industry of the People's Republic of China Ministry of Transport of the People's Republic of China.1995. Several issues concerning the examination, approval and administration of experimental foreign-invested concession projects circular. China.

Sun, Y.; Guo, J.; Gao, F.; Zhang, G. 2007. Influencing factors of government guarantee in infrastructure project financing, Statistics and Decision 20: 53-56.

Tam, C. M. 1999. Building-operation-transfer model for infrastructure developments in Asia: reasons for successes and failures, International Journal of Project Management 17(6): 377-329. http://dx.doi.org/10.1016/S0263-7863(98)00061-1

Tiong, R. L. K. 1997. Financial commitments for BOT project, International Journal of Project Management 15(2): 73-78. http://dx.doi.org/10.1016/S0263-7863(96)00033-6

Van Ham, H.; Koppenjan, J. 2001. Building public-private partnerships: assessing and managing risks in port development, Public Management Review 3(4): 593-616. http://dx.doi.org/10.1080/14616670110070622

Wang, L.; Yang, N. D.; Guo, X. 2006. Optimal timing of the entry and reconstruction for the BOT project based on real option theory, in Proceedings of the Eighth International Conference on Industrial Management, 2006, Beijing, China, 572-577.

Wong, K. P. 2007. The effect of uncertain on investment timing in a real options model, Journal of Economic Dynamics and Control 31(7): 2152-2167. http://dx.doi.org/10.1016/j.jedc.2006.07.002

Xia, X.; Li, H. 2009. ROI: Leading indicators for social capital invested in infrastructure, Modern Finance and Economics 29(6): 55-58.

Xiaocheng, F.; Yaokuang, L.; Dan, L. 2008. Evaluation of target enterprise in M\&As based on growth option, Value Engineering 5: 52-53.

Yang, P.; Liu, X. 2005. Dynamic balance analysis on credit crisis in BOT projects, Commercial Research 13: 156-157.

Zhang, G.; Guo, J. 2009. Research on infrastructure financing projects' incentive and monitor problems, Soft Science 23(3): 76-93.

Zhang, G.; Guo, J.; Zhao, Q. 2006. Real option value research of fixed price "Take or Pay" government purchasing agreement, in Proceedings of the Third International Conference on Risk Management \& The Fourth International Conference on Financial System Engineering, 2006, Qingdao, China.

Zhang, Z. 1999. The value of liability guarantee, Research on Financial and Economic Issues 6: 22-27. 
Qingpeng MAN. Associate Professor and Assistant Chairman of Department of Real Estate and Construction, School of Management, Harbin Institute of Technology, Harbin, China. Member of Construction Economy of Architectural Society of China. His research interests are in infrastructure management, construction risk management, and information management in construction.

Chengshuang SUN. Associate Professor and Chairman of Department of Real Estate and Construction, School of Management, Harbin Institute of Technology, Harbin, China. Deputy Secretary-general and member of Professional Committee of Management Modernization of China. His research interests are in sustainable construction; information management for construction engineering; and risk management for construction engineering.

Yuesheng FEI. Senior manager of Industrial Securities Co.,Ltd,15 Jinrong St, Xicheng, Beijing, China. His research interests are in the financing of infrastructure and government behavior.

Martin SKITMORE. Professor of School of Civil Engineering and Built Environment, Queensland University of Technology, Gardens Point, Brisbane, Australia. His research interests include statistical modelling for bidding and cashflow; sustainable development; use of information technologies; and urbanization in China.

Yong BAI. Chair and Professor of Department of Construction Management and Engineering, North Dakota State University, Fargo, USA. Professional engineer of State of Texas, Fellow of American Society of Civil Engineers, Member of American Society for Engineering Education, and Specially Editor of Journal of Construction Engineering and Management. His research interests are in infrastructure construction and maintenance, highway work zone safety, emerging technology applications, and international construction management.

Weizhuo LU. Senior lecture of Department of Civil, Environmental and Natural Resources Engineering, Luleå University of Technology, Luleå, Sweden. His research interests are in Construction Engineering and Management. 